\title{
Alain-René Lesage, Fuvres complètes, t. 8, Histoire d'Estévanille Gonzalez surnommé le garçon de bonne humeur, Le Bachelier de Salamanque ou les mémoires de Don Chérubin de la Ronda
}

\section{Paola Perazzolo}

\section{OpenEdition}

\section{Journals}

Edizione digitale

URL: http://journals.openedition.org/studifrancesi/5953

DOI: $10.4000 /$ studifrancesi.5953

ISSN: 2421-5856

Editore

Rosenberg \& Sellier

\section{Edizione cartacea}

Data di pubblicazione: 1 mai 2011

Paginazione: 171

ISSN: 0039-2944

\section{Notizia bibliografica digitale}

Paola Perazzolo, «Alain-René Lesage, Euvres complètes, t. 8, Histoire d’Estévanille Gonzalez surnommé le garçon de bonne humeur, Le Bachelier de Salamanque ou les mémoires de Don Chérubin de la Ronda», Studi Francesi [Online], 163 (LV | I) | 2011, online dal 30 novembre 2015, consultato il 08 janvier 2021 URL: http://journals.openedition.org/studifrancesi/5953 ; DOI: https://doi.org/10.4000/studifrancesi. 5953

Questo documento è stato generato automaticamente il 8 janvier 2021.

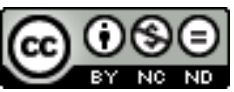

Studi Francesi è distribuita con Licenza Creative Commons Attribuzione - Non commerciale - Non opere derivate 4.0 Internazionale. 


\title{
Alain-René Lesage, Euvres complètes, t. 8, Histoire d'Estévanille Gonzalez surnommé le garçon de bonne humeur, Le Bachelier de Salamanque ou les mémoires de Don Chérubin de la Ronda
}

\author{
Paola Perazzolo
}

\section{NOTIZIA}

ALAIN RENÉ LESAGE, Euvres complètes, t. 8, Histoire d'Estévanille Gonzalez surnommé le garçon de bonne humeur (ed. critica di Cécile Cavillac), Le Bachelier de Salamanque ou les mémoires de Don Chérubin de la Ronda (ed. critica di Guiomar Hautcœur), Paris, Champion («Sources classiques», 93), 2010, pp. 815.

Ottavo tomo delle CEuvres complètes (quarto delle Euvres romanesques) edite sotto la direzione di Christelle Bahier-Porte e Pierre Brunel, il volume ha il merito di presentare due testi poco noti di Lesage. Nell'«Introduction», Cécile CAVILLAC rievoca le pretese di utilità morale e le circostanze di composizione della Histoire d'Estévanille González surnommé le garçon de bonne humeur; l'opera, redatta in un periodo di intensa produzione narrativa (1734-1741), appare al contempo come «un exercice d'autoimitation», che riprende temi, episodi e situazioni già sfruttati nei primi tre volumi di Gil Blas o in Guzmán d'Alfarache, e come un «adattamento» di scritti storici, della produzione spagnola in generale e, per quanto riguarda la struttura, de La vida y hechos de Estebanillo González, hombre de buen humor, compuesto por el mismo in particolare. Il risultato è un romanzo discontinuo, un centone in cui Lesage giustappone episodi «tant de [son] propre fonds» che «de plusieurs auteurs castillans» facilmente adattabili al gusto francese. Completa l'introduzione l'evocazione della fortuna di un testo 
abbastanza apprezzato al momento della pubblicazione ma in seguito scarsamente riedito e poco considerato dalla critica.

Le Bachelier de Salamanque ou les mémoires de Don Chérubin de la Ronda - di cui purtroppo l'editore non ha potuto consultare la seconda edizione del 1736 conservata al British Museum - è, come afferma Guiomar Hautecœur, un testo molto «méconnu» a causa del precedente difficile accesso (l'ultima edizione risaliva al 1903), dell'accusa di plagio formulata già da Voltaire - che ha per secoli ingiustamente pesato sulla sua fortuna, di giudizi critici che lo qualificano come un'opera puramente «alimentare», caratterizzata da un meccanismo di auto-citazione e auto-imitazione che tuttavia secondo l'editore "participe moins d'un essoufflement que d'une logique interne propre à l'univers fictionnel lesagien» (p.396). Anche il Bachelier dovrebbe infatti essere inserito nella «trilogie picaresque» di un autore che se riprende dalla tradizione picaresca molti materiali, impone anche nel contesto francese dei primi decenni del Settecento un immaginario picaresco riformulato in un universo poetico proprio, che a livello di descrizione della società e di forme letterarie adottate rispecchia più il contesto d'arrivo che quello d'origine: non solo il romanzo oscilla tra la ripresa del codice dell'autobiografia picaresca e l'adozione della più recente tradizione degli pseudomémoires, ma si stacca anche dalla formula spagnola per l'assenza di una presa di posizione relativamente alla finalità morale che dovrebbe o meno sottendere lo scritto di un memorialista.

3 Presentati secondo i criteri delle Euvres complètes con ortografia, accentazione e punteggiatura modernizzate, corredati da note linguistiche ed esplicative relative a fonti e collegamenti intertestuali con altre opere dell'autore, completati da una bibliografia, un glossario e una parte annessa che dà conto di varianti troppo estese per essere poste in nota, l'Histoire d'Estévanille González e il Bachelier de Salamanque fanno parte, come sottolinea Cécile Cavillac, della produzione di un «maître écrivain dont la qualité de style n'est pas une simple compensation aux défaillances de la conception» (p.9). Benché penalizzati da un indubbio affievolirsi dell'ispirazione, questi restano comunque romanzi «indispensable[s] à la connaissance de l'œuvre de Lesage comme à celle de la production romanesque de l'Ancien Régime en général» (p. 25). 